\title{
UMA PROFESSORA ESTAGIÁRIA EM SUA CAMINHADA EM BUSCA DA APRENDIZAGEM AUTÔNOMA*
}

\author{
Bruna Braga Silveira \\ Bruna Sommer Farias \\ Caroline Scheuer Neves \\ Daniela Mittelstadt \\ Christine Nicolaides (orientadora)**
}

\begin{abstract}
RESUMO: Este é um trabalho de cunho qualitativo baseado em principios etnográficos, cujo objetivo principal é acompanhar e compreender o processo de desenvolvimento de aprendizagem e ensino autônomos. Os dados provêm de uma pesquisa intitulada "O Professor de Língua Inglesa e sua Trajetória em Direção ao Aprendizado e ao Ensino Autônomos", que procura verificar o comportamento de cinco participantes em dois momentos - como alunos da disciplina de Prática de Ensino de Língua Inglesa de uma universidade particular em Porto Alegre, e como estagiários em escolas da rede pública estadual. Para este trabalho, no entanto, descreveremos a experiência de apenas uma participante: Mariana $^{l}$. Os resultados mostram o engajamento da participante em planejar e aplicar tarefas significativas objetivando desenvolver a autonomia em seus aprendizes.
\end{abstract}

PALAVRAS-CHAVE: Autonomia - Estágio de Inglês - Aprendizagem de línguas

ABSTRACT: This paper is based on qualitive research with ethnographical principles, which aims to follow and understand autonomy learning process development. The data come from a research project entitled "The English teacher and his/her trajectory towards autonomous learning and teaching", whose main objective is to verify the behavior of five participants at two occasions-as students during the intraining teaching classes in a private university in Porto Alegre, and as student-teachers during their intraining teaching period in state public schools. Nevertheless, for this paper we will be describing the experience of only one participant: Mariana. Results show the participant commitment while planning and applying meaningful tasks which aim at her student's autonomy development.

KEYWORDS: Autonomy - In-training period - Language learning

\section{INTRODUÇÃO}

Quando se tem em mente desenvolver a autonomia de professores e aprendizes no ensino e aprendizagem de línguas, além de um embasamento teórico que esclareça as

\footnotetext{
* Este trabalho é uma versão estendida do trabalho apresentado durante o IX Salão de Iniciação Científica da PUCRS - 2008.

** Bruna Braga Silveira - bolsista de IC - UFRGS, brusilveirahhh@hotmail.com.

Bruna Sommer Farias - bolsista de IC - UFRGS, brunasommer@live.com.

Caroline Scheuer Neves - bolsista de IC - UFRGS, carol-sn@hotmail.com.

Daniela Mittelstadt - bolsista BIC - UFRGS, daniela.doneda@gmail.com.

Christine Nicolaides - doutora em Letras e professora adjunta - UFRGS, nicolaides@terra.com.br.

${ }^{1}$ Nome fictício.
} 
diferentes perspectivas conceituais da área, fazem-se necessários estudos que descrevam os caminhos trilhados por professores e aprendizes de língua em direção à aprendizagem autônoma.

Este trabalho tem por objetivo relatar a experiência da professora estagiária Mariana e seus alunos de $5^{\text {a }}$ série em aulas de Inglês, no sentido de melhor compreender que fatores parecem influenciar o desenvolvimento do ensino e aprendizado autônomos.

$\mathrm{Na}$ próxima seção, trazemos à tona algumas das concepções de autonomia na área de Lingüística Aplicada desde as mais clássicas, associadas ao indivíduo, até àquelas associadas ao contexto social. Após, apresentamos os procedimentos metodológicos adotados na pesquisa e, em seguida, a análise dos dados constituída a partir: das expectativas iniciais da participante como aluna da disciplina de Prática de Ensino, das impressões das primeiras aulas por ela captadas e, finalmente, da nossa constatação de como Mariana implementou seu projeto de trabalho e os obstáculos daí advindos.

\section{PRESSUPOSTOS TEÓRICOS}

A mais tradicional concepção de autonomia a define como "a habilidade de encarregar-se por sua própria aprendizagem" (HOLEC, 1981, p. 3). Já Nicolaides (2003, p. 38), apresenta uma visão mais política de autonomia. Segundo a autora, ser um aprendiz autônomo significa:

\footnotetext{
Saber definir suas metas; entender seu papel de aprendiz como responsável pelo processo de busca e aquisição do conhecimento; estar apto a definir as formas de buscar seu conhecimento, desenvolvendo habilidades e técnicas para trabalhar de forma independente e em outros contextos diferentes do acadêmico; ser capaz de detectar suas dificuldades e procurar soluções para serem implementadas tendo maior controle sobre sua aprendizagem; conseguir avaliar-se não só ao final, mas durante o processo de aprendizagem; desenvolver a capacidade de exercer autonomia como aprendiz nas oportunidades oferecidas pelo contexto, de forma responsável e assim, tomar consciência de seu papel de modificador do meio social no qual está inserido.
}

Para que o aluno consiga desenvolver sua própria autonomia, o papel do professor é fundamental e ele, por sua vez, também deverá ser um profissional autônomo. Para tanto, de acordo com Fernandes (2005, p. 204), o professor autônomo é: "Aquele que quer e tem condições de fazer a negociação entre os constrangimentos educacionais e suas intenções pedagógicas".

Para analisar as características dos alunos, tomamos a noção de autonomia proativa e reativa defendida por Littlewood (1999, p. 75). Segundo o autor, autonomia proativa concerne à capacidade do indivíduo de pensar em seus próprios objetivos, de modo a direcioná-los em busca de métodos para adquirir conhecimentos e de uma autoavaliação crítica de seu próprio aprendizado. Há ainda, a idéia de autonomia reativa, que não parte de decisões individuais, mas baseia-se em um direcionamento inicial e, a partir disso, o indivíduo é capaz de construir seu próprio caminho em busca de uma aprendizagem mais significativa.

Finalmente, é importante salientar que não é adequado simplesmente definir os aprendizes - sejam alunos, sejam professores - simplesmente como autônomos ou não, 
independentemente da perspectiva adotada. Isso implica uma análise em termos de identidade. O aprendiz de língua é aceito como um ser complexo, alguém que possui uma identidade mutável ao longo do tempo e em diferentes contextos. Bonny Norton é uma das autoras que defende a idéia de identidade social múltipla, suscetível a mudanças. Segundo a autora:

\begin{abstract}
A língua não é concebida como um meio neutro de comunicação, mas entendida como uma referência de seu significado social. Enquanto os aprendizes falam estão constantemente organizando e reorganizando suas identidades e como se relacionam com o mundo - estão permanentemente construindo e negociando suas identidades. (NORTON, 1995, p. 410)
\end{abstract}

Sendo assim, com base nas idéias de que aprendemos quando somos responsáveis pelo processo da aprendizagem e de que, para isso, estamos em constante negociação de nossas identidades como aprendizes, buscamos entender como a participante da pesquisa procura desenvolver, ou não, a autonomia de seus alunos através de sua prática.

\title{
PROCEDIMENTOS METODOLÓGICOS
}

Para este trabalho foram analisados, como já referido, apenas os dados gerados a partir da participante Mariana. Os métodos utilizados foram previamente testados em outras pesquisas sobre autonomia (NICOLAIDES, 2003; FERNANDES, 2005), que mostraram a sua validade e importância para o entendimento do aprendizado autônomo. Estes métodos foram:

$\checkmark$ duas oficinas sobre o tema autonomia, durante as aulas de Prática de Ensino (ministradas pelas pesquisadoras com a presença de todos os estagiários, bem como da supervisora da disciplina), antes do início do estágio. Foi feita a discussão a respeito dos objetivos e procedimentos da pesquisa, bem como sobre algumas concepções de autonomia na aprendizagem de L2;

$\checkmark$ observação e registro por meio de filmagem e posterior transcrição de três aulas de Inglês ministradas pela estagiária;

$\checkmark$ uma sessão de visionamento feita ao final do semestre em que todos os estagiários assistiram e teceram comentários sobre uma das aulas de Mariana. Essas sessões foram igualmente transcritas para posterior análise;

$\checkmark$ e-mails com as principais impressões da estagiária sobre suas aulas, enviados ao grupo de pesquisa, à supervisora e aos colegas de Prática de Ensino. Nesses, Mariana expressou suas expectativas e angústias, apresentou seus planos de aula e considerações acerca do desenvolvimento de seus alunos em relação ao conceito de autonomia.

Mariana estagiou em uma escola da rede pública estadual da cidade de Porto Alegre. Os alunos da referida escola eram oriundos, em sua maioria, de classe médiabaixa e baixa. As aulas observadas eram de Inglês, em uma turma de $5^{\text {a }}$ série, turno da tarde, ministradas por Mariana duas vezes na semana (aulas de 45 minutos). A turma era composta por 21 alunos com faixa etária entre 10 e 12 anos, sendo 8 meninas e 13 
meninos. Um fato que nos chamou a atenção foi o engajamento dos alunos na manutenção da sala de aula. Eles eram, por exemplo, uma vez por semana, incumbidos de varrê-la.

\section{ANÁLISE DE DADOS}

Nesta seção analisaremos o comportamento e as atitudes da professora estagiária e seus alunos, ao tentar desenvolver o aprendizado autônomo em relação:

$\checkmark$ às expectativas de Mariana sobre suas aulas de estágio;

$\checkmark$ às suas primeiras impressões no seu contato com os alunos;

$\checkmark$ à implementação de seu projeto de trabalho e os entraves daí oriundos;

$\checkmark$ às soluções encontradas para os obstáculos.

\section{Expectativas iniciais da participante como aluna da disciplina de Prática de Ensino}

Mariana, na época da geração de dados desta pesquisa, tinha 21 anos e encontrava-se no penúltimo semestre do curso de Letras Português - Inglês. Como aprendiz, pôde-se observar que era participativa nas discussões propostas pela professora, assim como nos momentos em que interagia nas oficinas organizadas pelas pesquisadoras. Além disso, mostrava-se motivada em relação ao seu estágio:

\section{E-mail enviado em 06/09/2007}

I'm getting pretty nervous... I'm going to start teaching in the end of this month!

I have many ideas... but I have to write them down... otherwise, I forget! heheheheh... I've talked to my supervisor about my plans and she said they are really good... ${ }^{2}$

Outra questão a ser mencionada é o fato de Mariana ter observado sua turma antes do início de seu estágio, quando as aulas ainda estavam sendo ministradas pela professora titular de Inglês. Durante as oficinas, Mariana declarou ter observado aspectos desfavoráveis nas aulas da professora titular, os quais não pretendia utilizar como modelo para suas aulas. Um exemplo das perspectivas da estagiária pode ser verificado nas anotações de diário das pesquisadoras:

Observações sobre a oficina 2 durante a aula de Prática de Ensino em
27/08/2007
Ela já vem observando a turma há algumas semanas. Ela fez uma crítica à
professora titular que parece "cansada", segundo suas próprias palavras
(Mariana). A professora titular, de acordo com ela, não está motivada
suficientemente para preparar as atividades. São 21 alunos de uma $5^{\text {a série. }}$
Disse também que os alunos possuem um grande potencial, que não é
explorado pela professora. Ela afirma que o que a professora trabalha não é

\footnotetext{
${ }^{2}$ [Estou ficando nervosa... Eu vou começar a dar aulas no fim deste mês! Eu tenho muitas idéias... mas eu tenho que passá-las para o papel... do contrário, eu esqueço! Heheheheh... Eu conversei com minha supervisora sobre meus planos e ela disse que eles são muito bons...]
} 


\begin{abstract}
"meaningful" para os alunos. Deu algumas idéias de como poderia ter sido trabalhada a atividade sobre dias da semana proposta pela professora. Por exemplo, envolvendo aniversários dos alunos. Ela parece bastante ansiosa para assumir a turma. De acordo com Mariana, os alunos também têm boas perspectivas para tê-la como estagiária.
\end{abstract}

No que concerne ao seu background profissional, Mariana possuía uma boa competência lingüística e experiência prévia em cursos livres de língua. É interessante observar a declaração que fez a respeito de sua liberdade ao preparar as aulas em seu então local de trabalho. Essa discussão se deu durante a segunda oficina em que o grupo discutia diferenças entre autonomia proativa e reativa, já explicitadas anteriormente:

Transcrição da oficina 2 em Prática de Ensino em 27/08/2007

Mariana: [...] my boss I know her for a long time and I think she:: is very confident about my job, what I do to my students, and I think she gives me all the space and:: what I need to do my things

Pesquisadora: so as a teacher you feel you feel you have this ah:: ah:: space for being proactive,

Mariana: yes.

Pesquisadora: ok, and ah:: what about your students? do you think your students have space to be proactive?

Mariana: yes some yes because they are like they got me crazy but I like them and they are very like dynamic and ( )

Pesquisadora: ok so they are ah ( ) they are engaged ( )

Mariana: yes.

Pesquisadora: can you give us an example?

Mariana: I don't know when I do strange things with ah:: ye::s because I don't like saying let's listen to the tape and ( ) I think it's too boring because if I was a student like if I were in their places I wouldn't like to do those things and even with like simple things I ask them to shout or to do something different can be like repetition sometimes ah repeat that no but louder no no go up the chair and scream and they love that and my boss she supports me on this because she said they love my classes and they get out of it very very like I don't know aliviados. ${ }^{4}$

\footnotetext{
3 [Significativo]

4 [Mariana: minha chefe, eu a conheço há tempos e eu acho que ela confia bastante no meu trabalho, o que eu faço para meus alunos, e eu acho que ela me dá todo o espaço e o que eu preciso para fazer minhas coisas.

Pesquisadora: então, como professora, você sente que tem esse espaço para ser proativa.

Mariana: sim.

Pesquisadora: certo, e sobre seus alunos? você acha que seus alunos têm espaço para serem proativos?

Mariana: sim, alguns sim, porque eles são como, eles me deixam louca, mas eu gosto deles e eles são bem dinâmicos e ( ).

Pesquisadora: certo, então eles são ah ( ) eles são engajados ( )

Mariana: sim.

Pesquisadora: você pode nos dar um exemplo?

Mariana: eu não sei, quando eu faço coisas estranhas com ah, sim, porque eu não gosto de dizer vamos ouvir a fita e ( ) eu acho que isso é muito chato, porque se eu fosse um aluno, como se eu estivesse no lugar deles, eu não gostaria de fazer essas coisas e mesmo com coisas simples eu peço pra eles gritar ou fazer algo diferente, pode ser como repetição, às vezes ah repita, não, mas mais alto, não não, levante da cadeira e grite e eles adoram isso, e minha chefe, ela me apóia nisso porque ela diz que eles adoram minha aula e eles saem dela muito muito, não sei, aliviados.]
} 
Em um trecho do dado apresentado, Mariana afirma acreditar que seus alunos têm, assim como ela, espaço em suas aulas para desenvolver a autonomia proativa. Podemos perceber a confiança da supervisora nas tarefas propostas pela estagiária, de modo a motivá-la e incentivá-la na construção de tarefas contextualizadas e criativas que possibilitem o desenvolvimento das mesmas habilidades em seus alunos. A partir desta dinamicidade, os alunos acabam por engajar-se da mesma forma no processo de aprendizagem. Um exemplo disso pôde ser verificado durante uma das tarefas propostas por Mariana. Nela, a estagiária aproveitou os conhecimentos aprendidos pelos alunos na disciplina de Ciências - a classificação dos animais em mamíferos, aves, répteis e insetos. A professora distribuiu entre os alunos figuras de animais pertencentes a diferentes classes. Os alunos deveriam reconhecer a categoria a qual pertencia o animal estampado no cartão recebido e, quando a professora mencionasse a classe dos animais, deveriam levantar-se de suas cadeiras:

Transcrição da aula 1 em 29/10/2007

Mariana: quando eu falar assim mammals $^{5}$, todos que são mamíferos vão se levantar

Érika fala com colega: mas é, tá nos passarinhos, passarinho voa!

Marcos: o teu é mamífero, Mateus? deixa eu ver.

Mariana: eu falo insect ${ }^{6}$. todos que tem butterfly $^{7}$, bee $^{8}$, ( ) tem que

levantar.

João: levantar da cadeira ou levantar o dedo?

Mariana: da cadeira. tá, vamos ver.

Carlos: sora, não tem que falar nada?

Mariana: não, agora não. pessoal, presta atenção! atençã::o! REPTILE. ${ }^{9}$

((alguns alunos se levantam))

Érika: SE LEVANTA, GURI!

Mariana: Léo, falta o teu!

Pode-se perceber que a tarefa proporciona momentos de interação entre os aprendizes, nos quais acionam seus conhecimentos de Ciências e em que uns interferem nas ações dos outros. A autonomia parece ser estimulada por parte dos alunos na medida em que, com o objetivo de cumprir a tarefa proposta, tomam a iniciativa de checar e discutir não somente suas opções, mas também as dos colegas. Momentos como esse são, sob nosso ponto de vista, de bastante aprendizagem para todo o grupo.

\section{As impressões da estagiária de suas primeiras aulas}

O início do estágio de Mariana é caracterizado pela construção de um acordo entre ela e seus alunos sobre como eles deveriam se comportar. A estagiária apresenta grandes expectativas em relação ao trabalho a ser desenvolvido. Os alunos, por sua vez, parecem acolhê-la e depositar confiança de que terão uma aprendizagem bem sucedida. Assim, comprometem-se em colaborar mais no processo. Isso pode ser constatado pelo e-mail escrito por Mariana descrevendo sua primeira aula:

\footnotetext{
${ }^{5}$ [Mamíferos]

${ }^{6}$ [Insetos]

${ }^{7}$ [Borboleta]

8 [Abelha]

${ }^{9}$ [Répteis]
} 


\begin{abstract}
E-mail enviado em 28/09/2007
One thing that I liked a lot was that, whenever I wanted to talk, many students called the others' attention because I wanted to say something, they cooperated with me.

I did a review, they participated, they talked a lot, they asked questions to their classmates in English, etc.

In the end of the class, one of the kids, a boy, his name is Nathan, said: "Teacher, I know we talked a lot in class today and I know that I didn't participate as you expected. Next class, we will be calmer and better. You are a very good teacher. I'm sorry." After he said that, everybody agreed with him and we made another deal.

They were asking silence all the time. I think this cooperation was something that I wasn't expecting, that they would like my presence there and from what I could see, they think I'm their last hope. ${ }^{10}$
\end{abstract}

A última declaração de Mariana é bastante expressiva. Podemos interpretar as palavras "última esperança" de duas formas: a turma tem uma auto-imagem de barulhentos e, de certa forma, indisciplinados; Mariana parece representar a esperança de que esse quadro mude. Outra interpretação, que não exclui a primeira, é a expectativa, por parte dos aprendizes, de que haja de fato uma aprendizagem eficaz e significativa.

Em uma aula posterior, Mariana envia outro e-mail, agora com uma impressão mais próxima da realidade de seus alunos. Vejamos seu e-mail:

\author{
E-mail enviado em 01/10/2007 $7^{11}$ \\ YOU KNOW... TODAY I DECIDED THAT I'M NOT GOING TO BE AN \\ ENGLISH TEACHER ANYMORE... I'M GOING TO BE A GENERAL \\ KNOWLEDGE ONE... HEHEHEHEHE... \\ TODAY, I TAUGHT SOME COUNTRIES AND NATIONALITIES, AND I \\ TOOK A MAP (MAPA MUNDI)... SOME OF MY STUDENTS GOT \\ REALLY CLOSE AND 'STUDIED' THE MAP... THEN I ASKED THEM: \\ "WHERE IS BRAZIL?" AND THEY COULDN'T TELL ME... I SHOWED \\ THEM... AND ASKED OTHER QUESTIONS... VERY INFORMAL AND \\ THIS WASN'T IN MY LESSON PLAN BUT I NEEDED TO SHOW \\ THEM WHERE SOME COUNTRIES ARE AND THINGS LIKE THAT, \\ BECAUSE I THINK THEIR GEOGRAPHY TEACHER HAS NEVER TAKEN \\ A MAP AND LET THEM EXPLORE IT... \\ WHEN I ARRIVED I WAS VERY EXCITED WITH THE CLASS I'D \\ PLANNED... AND THEY COULD SEE IT IN THE WAY I WAS \\ SPEAKING TO THEM, MY GESTURES.... SO THEY GOT MOTIVATED \\ TOO. IT WAS VERY GOOD, I TAUGHT THEM THE QUESTIONS: \\ "WHERE ARE YOU FROM?" AND "WHAT'S YOUR NATIONALITY?" I
}

\footnotetext{
${ }^{10}$ [Uma coisa que eu gostei bastante foi que, sempre que eu queria falar, muitos alunos chamavam a atenção dos outros porque eu queria dizer alguma coisa, eles cooperaram comigo. Eu fiz uma revisão, eles participaram, eles falaram bastante, eles fizeram perguntas para seus colegas em Inglês, etc. No final da aula, uma dessas crianças, um menino, o nome dele é Nathan, disse: "Professora, eu sei que nós falamos muito na aula hoje, e eu sei que eu não participei como você esperava. Na próxima aula nós estaremos mais calmos e melhores. Você é uma professora muito boa. Me desculpe". Depois que ele disse aquilo, todo mundo concordou com ele e nós fizemos outro acordo. Eles estavam pedindo silêncio o tempo inteiro. Eu acho que essa cooperação foi algo que eu não estava esperando, que eles gostariam da minha presença lá e, pelo que eu pude ver, eles acham que eu sou a última esperança deles.]

${ }^{11}$ A estagiária utilizou-se de Caixa Alta para escrever este e-mail. Como isso pode ter sido intencional por parte da autora, optamos por manter a formatação original.
} 
GAVE THEM SOME CARDS WITH NAMES OF FAMOUS PEOPLE AND THEIR NATIONALITY, SO THEY HAD TO TALK LIKE THEY WERE THE CELEBRITIES... IT WAS REALLY FUNNY, AND EVERYBODY WANTED TO SAY WHAT CELEBRITY THEY WERE... I FELT REALLY PROUD OF THEM BUT AT THE SAME TIME, VERY WORRIED.

ONE OF THE KIDS, WHEN THE CLASS FINISHED, ASKED ME... "TEACHER, WHICH FLAG REPRESENTS BRAZIL?"

THEN I SHOWED HIM AND HE WENT TO THE BREAK REALLY... I DON'T KNOW HOW TO SAY IT... BUT THIS CLASS WAS BETTER THAN THE FIRST ONE! AND I THINK THEY FELT THE SAME! ${ }^{12}$

A constatação feita por Mariana é relevante não só para o ensino de línguas, mas para o cenário educacional em geral. Como professores, muitas vezes planejamos tarefas que, sob nossa ótica, são apropriadas para nossos aprendizes. Temas como nacionalidade/origem, por exemplo, estão comumente presentes nos materiais didáticos e em salas de aula de L2. Todavia, nem sempre estamos prevenidos para situações como a que ocorreu na sala de aula de Mariana - falta de conhecimento básico de Geografia por parte dos alunos. No entanto, a reflexão feita por ela representa um fator importante quando pensamos na implementação de um aprendizado autônomo: como se pode esperar que os alunos sejam autônomos se não tiverem o embasamento que supomos ser de seu domínio para aquisição de um novo conhecimento?

Segundo os Parâmetros Curriculares Nacionais (PCN (1998, p. 39)),

(...) a aprendizagem de Língua Estrangeira aguça a percepção e, ao abrir a porta para o mundo, não só propicia acesso à informação, mas também torna os indivíduos e, conseqüentemente, os países, mais bem conhecidos pelo mundo. Essa é uma visão de ensino de Língua Estrangeira como força libertadora de indivíduos e de países.

Os PCN (1998) mostram a importância de não apenas ensinar a língua, mas a de formar indivíduos. Podemos perceber que Mariana procura cumprir o seu papel não só de "fornecedora de conteúdos" de Inglês, mas reconhece a importância de ser também uma fonte de conhecimento geral. O que a participante busca fazer, na verdade, é que seus alunos façam uma ligação entre o que conhecem sobre a realidade local na qual estão inseridos e uma mais abrangente - a de mundo.

\footnotetext{
12 [Você sabe... hoje eu decidi que eu não vou mais ser professora de Inglês... Eu serei uma professora de conhecimentos gerais... hehehe... Hoje, eu ensinei alguns países e nacionalidades, e eu trouxe um mapa (Mapa Mundi)... alguns dos meus alunos chegaram bem perto e 'estudaram' o mapa... então eu perguntei a eles: "Onde é o Brasil?" e eles não conseguiram me dizer... eu mostrei a eles... e fiz outras perguntas, bem informal, e isto não estava no meu plano de aula, mas eu precisei mostrar-lhes onde ficavam alguns países e coisas desse tipo, porque eu acho que a professora de Geografia deles nunca tinha levado um mapa e deixado eles explorá-lo... Quando eu cheguei, eu estava muito animada com a aula que eu havia planejado... e eles podiam ver isso no jeito que eu estava falando com eles, meus gestos... então eles ficaram motivados também, isso foi muito bom, eu os ensinei as perguntas: "de onde você vem?" e "qual é sua nacionalidade?" Eu entreguei a eles alguns cartões com nomes de pessoas famosas e suas nacionalidades, então eles tinham que falar como se eles fossem celebridades... foi realmente divertido, e todos quiseram dizer que celebridade eles eram. Eu me senti muito orgulhosa deles, mas ao mesmo tempo, muito preocupada. Uma das crianças, quando a aula terminou, me perguntou... "Professora, que bandeira representa o Brasil?" Então, eu mostrei a ele e ele foi para o recreio muito... eu não sei como dizer isso... mas essa aula foi melhor que a primeira! E eu acho que eles sentiram o mesmo!]
} 
Durante o ato pedagógico, outro fator a ser verificado na aula de Mariana são os diferentes momentos para a aprendizagem: o momento de motivação para aprender o novo ou revisar um conteúdo já estudado e o momento da organização mental do que foi aprendido. Os dois são relevantes para uma aprendizagem bem sucedida, especialmente quando lidamos com crianças. A busca do equilíbrio entre eles é fator fundamental para que o conhecimento seja significativo para o aprendiz. Um exemplo dessa preocupação nas aulas de Mariana pode ser detectado no excerto a seguir:

\footnotetext{
Observações da aula 1 do dia 29/10/2007

Professora revisa comandos em Inglês e vários participam. Professora trata os alunos com muita simpatia. A hora do desenho parece acalmar as crianças. Quando cada um tem sua própria atividade, o engajamento da turma é maior.

O exercicio que envolve desenho deixa-os mais calmos e concentrados.

$\cdots$

Um dos meninos veio nos mostrar o desenho. Eu (pesquisadora) elogio e ele sai feliz.

Apesar de alguns alunos não participarem das atividades propostas, muitos interagem com a professora.

A professora faz uma revisão da aula anterior; os alunos participam e parecem lembrar-se do conteúdo.
}

Como pode ser observado, Mariana inicia sua aula revisando conteúdos de Ciências em Inglês, o que proporciona interação e participação por parte dos alunos na tarefa. Instantes depois, no entanto, o momento em que cada aprendiz se concentra em seu trabalho, com o objetivo de cumprir uma tarefa, parece ser igualmente importante para a construção do novo conhecimento.

\section{A implementação do projeto de trabalho de Mariana e os obstáculos encontrados}

$\mathrm{Na}$ continuação de suas aulas, a estagiária demonstrou frustração, pois seus alunos não realizaram a tarefa por ela planejada. Convém explicar que a tarefa envolvia pesquisa a ser efetuada na biblioteca da escola, sobre diferentes culturas. Os alunos, no entanto, não tiveram uma boa resposta à sua solicitação. Uma de nossas hipóteses para esse comportamento é a falta de autonomia dos próprios alunos. A seguir, pode-se analisar os seus comentários sobre a aula:

\section{E-mail enviado em 08/10/2007}

Well, my third class was terrible... now, I feel so bad, that I'm crying...

I planned for this class, since we are studying countries, to expose them to some culture.

I took those pictures that you saw the other day and after that, they would research and present to the rest of the class what they knew about the place... In the beginning, everything was wonderful... I showed them the pictures, we brain-stormed...everybody was participating... I was really happy...

But, when I asked them to research and do something with that.... they simply chatted and did nothing.... I'm being cruel... 5 students did what I asked the others, 12, didn't. 
When they had to present, they just read... when I asked something.... they didn't know....and I asked them what I knew that was in the book they researched....

They weren't interested in doing anything... they wanted me to present it... and they would just sit and listen like walls....

I don't know how my wonderful class (in the beginning) turned out to be hell... I don't know if you understand what I mean!

What I want to say is... I'm not feeling happy about it and the only person who wants to help them (me), they don't care... ${ }^{13}$

Ao detectar a lacuna de seus alunos em termos de conhecimentos geográficos, Mariana resolveu, na aula seguinte, colocá-los em contato com fatores culturais de diferentes países. Contudo, sua intenção não foi bem sucedida. A falta de hábito dos aprendizes em realizar pesquisas por conta própria, bem como a crença de que o professor é quem deve apresentar fatos novos, prejudicou o bom andamento do ato pedagógico.

Com o decorrer de suas aulas, Mariana pareceu ter superado o obstáculo acima mencionado, como também algumas dificuldades institucionais. Entre elas, a troca de horário de suas aulas, que a impossibilitou de continuar ministrando duas aulas semanais. No último mês de aula, Mariana passou a ter contato apenas uma vez por semana com seus alunos.

Na última aula observada, pudemos verificar que os alunos de Mariana eram capazes de expressar dados sobre sua vida pessoal, vejamos o exemplo:

Transcrição da aula $3 \mathrm{em} \mathrm{07/12/2007}$

Mariana: o pessoa::1, como eu digo assim "meu nome é"

Alunos: my name is

Mariana: como é que eu digo a idade?

Alunos: ah:: ( )

Alunos: I'm eleven.

[alguns alunos se dirigem até a professora para dizer a resposta]

Mariana: pessoa::1. como eu digo "meu animal favorito é"

Aluno: meu animal favorito é!

Outros alunos: my favorite animal is...

Mariana: como eu digo meu cantor favorito é?

Alunos: my favorite singer is...

Mariana: como é que eu digo que eu sou do brasil?

Alunos: I am brasil?

Aluno: /'breizil/

Aluna: /bra'zil/

Mariana: meu aniversário é em

\footnotetext{
${ }^{13}$ [Bem, minha terceira aula foi terrível... agora, me sinto tão mal, que estou chorando... eu planejei para esta aula, em vista de nós estarmos estudando países, mostrar a eles um pouco de cultura. Eu peguei estas gravuras que vocês viram outro dia e depois disso, eles pesquisariam e apresentariam para o restante da turma o que eles sabiam sobre o lugar... No início, tudo foi maravilhoso... Eu mostrei a eles as gravuras, nós trocamos idéias... todo mundo estava participando... eu estava muito feliz... mas, quando eu pedi a eles para pesquisarem e fazerem alguma coisa com aquilo... eles simplesmente conversaram e não fizeram nada... eu estou sendo cruel... 5 alunos fizeram o que eu pedi e os outros 12, não. Quando eles tinham que apresentar, eles só leram... quando eu perguntava alguma coisa, eles não sabiam, e eu perguntei a eles o que eu sabia que estava no livro que eles tinham pesquisado... eles não estavam interessados em fazer nada... eles queriam que eu apresentasse... e eles apenas ficavam sentados e ouviam como paredes... eu não sei como a minha aula maravilhosa (no início) virou um inferno... eu não sei se vocês entendem o que eu quero dizer! O que eu quero dizer é... eu não estou me sentindo feliz sobre isso e a única pessoa que quer ajudá-los (eu), eles não se importam...]
} 


\begin{abstract}
Alunos: my birthday is
$[\ldots]$

(a professora passa uma folha)

Mariana: vocês vão completar com os dados de vocês

O mesmo fato pode ser confirmado pelas observações das pesquisadoras:

Observação da aula 3 em 07/12/2007

Um dos alunos estava de aniversário e todos cantaram "Happy Birthday". A professora ficou menos tempo explicando a matéria do que em aulas anteriores. Os alunos se acalmaram para desenvolver a atividade, como acontecera em outras aulas. Não demonstraram dificuldade em realizá-la. A aula foi baseada em um objetivo, o que envolveu os alunos (os alunos colavam as atividades desenvolvidas durante as aulas em grandes cartazes a serem expostos posteriormente).
\end{abstract}

Nos exemplos anteriores, pode-se verificar indícios de que a aprendizagem em sala de aula foi eficaz. Os dados mostram o engajamento dos alunos, o que, sob o nosso ponto de vista, facilita a aprendizagem de L2.

Outra peculiaridade da estagiária era sua crença de que não deveria ser autoritária, desse modo, jamais alteraria sua voz para um tom mais alto em suas aulas. Esse fato é interessante na medida em que houve situações nas quais os próprios aprendizes pediam silêncio aos colegas. Temos registros de momentos em que um dos alunos apresentava um comportamento bastante agitado que atrapalhava o andamento da aula, mas, mesmo assim, a professora se recusava a levantar sua voz. Essa atitude de Mariana pode ser confirmada na sessão de visionamento feita com base na mesma aula:

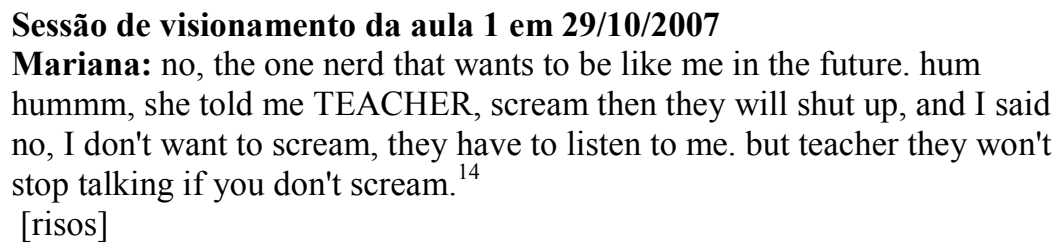

Em termos de autonomia, essa situação se apresenta um tanto paradoxal. A professora tentava estabelecer uma relação de cortesia, tranqüilidade e liberdade com seus aprendizes, todavia, a situação parecia, por vezes, "fugir do controle". Essa negociação entre a professora e os aprendizes, ao tentarem chegar a um consenso sobre o comportamento ideal na sala de aula, transcorreu durante todo o período de estágio.

Ao se pensar em autonomia, uma atitude não opressora parece essencial. Por outro lado, os dados apontam que o gerenciamento de sala de aula por parte do professor é fator preponderante no desenvolvimento da autonomia dos aprendizes (ver ainda MITTELSTADT; NICOLAIDES, no prelo).

\footnotetext{
${ }^{14}$ [Mariana: Não, a única nerd que quer ser como eu no futuro, humm humm, ela me disse, professora, grita, então eles vão calar a boca, e eu disse, não, eu não quero gritar, eles têm que me escutar. Mas professora, eles não vão parar de falar se você não gritar.]
} 


\section{CONSIDERAÇÕES FINAIS}

Pouco acrescentaria em termos de aprendizado autônomo, rotular um indivíduo simplesmente como autônomo ou não, considerando especialmente o conceito de identidades múltiplas (NORTON, 1995). Há uma rede complexa de fatores, como crenças, atitudes, estilos, que podem indicar um comportamento mais ou menos autônomo. O desenvolvimento da autonomia, inclusive, pode ser de maior ou menor grau em diferentes áreas. No caso de Mariana, ela demonstrou algumas características que apontam para as de uma aprendiz e, especialmente, as de uma professora engajada na questão da aprendizagem autônoma.

Uma dessas características é o seu senso crítico, no que tange aos resultados de seu trabalho no estágio. Além de sua capacidade de detectar problemas, a participante toma a frente na busca de soluções. Mariana ainda mostra um comprometimento para com seus alunos no sentido de proporcionar uma aprendizagem significativa. Esse comprometimento é por eles reconhecido, inclusive levando-os a verbalizar sua vontade de aprender.

A percepção de Mariana sobre a importância de organizar diferentes momentos de aprendizagem durante suas aulas e, acima de tudo, as suas atitudes para proporcionar esses momentos, surgem como fatores primordiais para o desenvolvimento autônomo de seus aprendizes. Parece claro que os alunos necessitam do momento de interação entre eles de forma que se motivem a aprender, tanto quanto precisam do momento de organização dos novos conhecimentos.

No que concerne aos alunos de Mariana, uma série de indicativos assinalam a falta de hábito inicial deles em responsabilizarem-se por sua aprendizagem. No entanto, na medida em que a professora dá oportunidades para que exerçam essa responsabilidade, fazendo-os perceber os objetivos a serem alcançados, o quadro parece mudar - os aprendizes claramente se engajam na aprendizagem e demonstram ter adquirido novos conhecimentos.

\section{REFERÊNCIAS}

FERNANDES, Vera. As crenças e a práxis de professores de língua inglesa em formação e o aprendizado autônomo. 2005. 219f. Tese (Doutorado em Letras) Instituto de Letras, Universidade Federal do Rio Grande do Sul, Porto Alegre, RS.

HOLEC, Henri. Autonomy in Foreign Language Learning. Oxford: Pergamon, 1981.

LITTLEWOOD, William. Defining and developing autonomy in East Asia contexts. Applied Linguistics, v. 20, n. 1, p. 71-94, 1999.

MITTELSTADT, Daniela \& NICOLAIDES, Christine. Gerenciamento de sala de aula $e$ atitudes dos aprendizes e professores para o desenvolvimento da autonomia em L2. Anais do II CLAFPL - PUC-RIO (no prelo).

NICOLAIDES, Christine. A busca da aprendizagem autônoma de língua estrangeira no contexto acadêmico. 2003. 235f. Tese (Doutorado em Letras) - Instituto de Letras, Universidade Federal do Rio Grande do Sul, Porto Alegre, RS.

NORTON PEIRCE, Bonny. Social identity, investment, and language learning. TESOL Quarterly, v. 29, n. 1, p. 9-31, 1995. 
SILVEIRA, B. B.; FARIAS, B. S.; NEVES, C. S.; MITTELSTADT, D.; NICOLAIDES, C.

Uma professora estagiária em sua caminhada em busca da aprendizagem autônoma.

PCN (1998). Brasil. Secretaria da Educação Fundamental. Parâmetros Curriculares Nacionais. Brasília: MEC/SEF, 1998. 